\title{
Hydro Development-Induced Environmental Impact on River Ecosystem
}

\author{
Qingran Wang \\ State Grid Xinyuan Company Ltd., Beijing, China \\ Email: star201@126.com
}

Received June 2013

\begin{abstract}
Based on the analysis of river ecosystem characteristics, the external problem of hydropower development is detailedly analyzed. Dam plays the important role in regulating regional water resources, reducing the storage of flood disaster, producing clean energy. However, the river system of morphology, topography, water quality and ecological environment are adversely affected. The controlling countermeasures of ecological compensation mechanism, the artificial cultivation of ecological system are proposed.
\end{abstract}

Keywords: Reservoir; Ecosystem; Environmental Impact; Externalities

\section{Introduction}

Hydropower development is an important engineering measure for dealing with water, and is an important way to protect the ecological environment (Shiklomanov, 2005). However, hydropower development will bring negative impacts on river basin. The paper analyzes the adverse effects of hydropower development on river ecological system. At the same time, the measure of reducing adverse effects of river ecological system is present.

\section{River Ecosystem Composition}

River ecosystem is the complex biological communities in the river and river environment interaction, the system is the series of subsystems from land riparian ecosystem, aquatic ecosystems, and wetlands to marsh ecological system which is open and continuous (Stegner, 1992).

From the endwise perspective, the river ecosystem includes upstream, middle, lower ways from the analysis of the vertical angle (Moyle, 1988). Most of the river originate in the mountains, flows through the hills, and is through to the estuary alluvial plain. The meteorological, hydrological and geological condition is very different which formats different mainstreams, tributaries, wetland, alluvial plain and flood plain.

From the horizontal perspective, the river ecosystem includes rivers, floodplains, riparian zone, and marshes. The river is the main body of the aquatic ecosystem, and is the main river ecological system. Floodplains are the river flood periodic region which includes shallow, shallow lakes and wetlands. Floodplain flood plays an important role in absorbing the flood, keeping the soil. Forests, grasslands, wetlands and marshes can maintain soil, prevent sediment into river.

From the vertical perspective, the aquatic ecological system of river ecological system can be divided into superficial, middle, bottom layer and the substrate. On the surface, oxygen is rich in water. Due to the flow of the river, the atmosphere of the large contact area and good gas exchange which is in favor of the decomposition for microbial survival and aerobic aquatic organisms. This is the main primary production water of aqua- tic ecosystem. In the lower layer, plankton is gradually reduced due to oxygen, sunlight is weakened. The basal rivers contain pebble, gravel, sand, clay and so on, which is the habitat for many organisms. At the same time, the aquatic ecological system carry out energy exchange continuously with the land bank system, wetland with material, which constitute the river ecosystem integrity.

From the time perspective, the river ecological system is changed with the passage of time, precipitation change, human disturbance, temperature fluctuation. The river is a living, in morphology, channel change may need very long time, but human disturbance effects on the river do not need too long time, such as water pollution, excessive water etc.

\section{Hydropower Development Affect on River Ecosystems}

Impact of hydropower development on river basin ecosystem environment is mainly reflected in two aspects which are river ecosystem impact on non-ecological factors and river ecosystem impact on ecological factors. River ecosystem impact on non-ecological factors are the characteristics of watershed hydrological, water, water, sediment, water, landforms, river morphology, the lower strata, regional climate. River ecosystem impact on ecological factors is primary production and higher trophic production which is interrelated and interacted. This change can be divided into three levels according to the effects of the depth (Hughes, 1990), as shown in Figure 1. The effects of hydropower development on river ecological system start from the influence on non-ecological factors. And then, changing is happened in the higher trophic level. The complexity of this interaction process is gradually increased from the first grade to the third grade.

\section{River Ecosystem Impact on Non-Ecological Factors}

1) Impacts on river systems in hydrological regime. Hydropower development is the controlling mode of flow change 


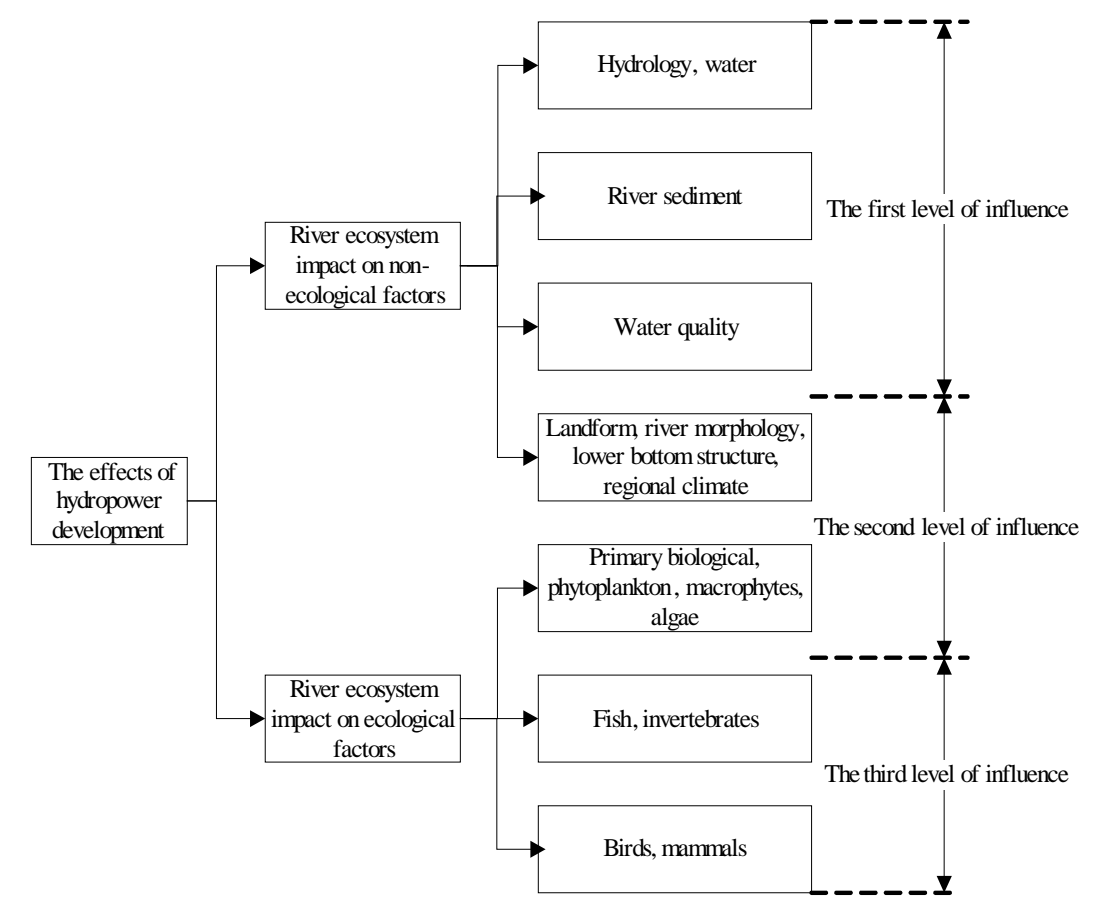

Figure 1.

Classification of effects of dam construction on riverine ecosystem.

artificially. The hydrological changes mainly happen in the rivers flow into the lake, sea water, river water, groundwater level variation. a) Changes in river flow, water level. The dam can change the natural flow pattern, has the capacity of flood storage and discharge. Reasonable regulation of river flow in the reservoir can reduce the peak flow of the river, flood controlling through to the combined use of river engineering downstream. The dam impounding water can make the seasonal rivers into a perennial River, which is more stable and adequate water irrigation to farmland, improve food production. Hydroelectric power generation makes by the river water level which is not only due to precipitation change, also will change because of power demand factors changing. b) The change of groundwater level. Surface water and groundwater in the basin is closely related. The river hydrological conditions changing will affect the level of groundwater, water quality. The dam upstream reservoirs make the surrounding groundwater level elevation, thus expanding the scope of the reservoir, leading to salinization and marsh land. At the same time, damming the river also reduces the source of groundwater recharge in the lower reaches of the dam base, resulting in a lowering of the groundwater level, large tracts of the original groundwater gravity irrigation districts lose gravity conditions, reducing the downstream area of water resource utilization which makes the adverse effects of irrigation.

2) Effects on the river morphology, relief system. a) Changes of river morphology. The river flows through the area of soil and rock by erosion, transportation, the part of sediment is deposited in front of the dam, the formation of backwater delta, the reservoir capacity is greatly reduced. The river bed rises gradually because of scouring substance in the local deposition of more downstream. b) Changing of delta and coast line. Delta is caused by the accumulation of sediment for hundreds of thousands of years, and is formed in the sediment compaction and marine erosion under the interaction of. The interception effect on sediment dam has deeply influenced the Delta and coastal area. Sediment reduction will make the coastal areas seriously eroded, and the effect from the estuary along the coastline extends far away.

3) Influence on water quality of the river system. Chemical, physical and biological changes in river and experience for the dam will greatly change the original water quality which is the reservoir water salinity increasing, reservoir water temperature stratification, library increased algal blooming. a) Salinity changes. Dam water will form the reservoir area wide, compared with the natural river, greatly increasing the exposure to the sun's surface area. In the arid regions in the hot climatic conditions, a large number of evaporation of water will lead to increase salinity in water. b) Changes of acidity. The dam upstream is reservoir submerged vegetation, dissolved oxygen consuming water, releasing large amounts of greenhouse gases and carbon dioxide, which will increase the water acidity, dissolve mineral accelerated Lake. c) Change of temperature. Usually, discharge from the reservoir depth of water, the water temperature is low in summer than in winter than in the river water, and release export from the reservoir near the top of the water, all the year round than the high water temperature. Outlet water discharges from the reservoir near the top, all the year round than the high water temperature. d) Change of algae. Dam traps sediment and nutrient retention, these nutrients are more susceptible to the reservoir water body eutrophication phenomenon. When the temperature is higher, the algae may be overbearing in the reservoir with rich nutrition, so that the water body smell bad.

\section{River Ecosystem Impact on Ecological Factors}

River ecosystem impacts on the ecological factors are re- 
flected in Table 1. 1) The impact on the ecological environment of the river. Dam construction provides good condition for the development of aquaculture, makes many reservoir become the aquatic product supply base. However, at the same time, flooded vast tracts of land also hindered the valley life network connections, influence of wild plant ecological environment of survival, reproduction of the original. a) Habitat and reproduction environment changes. The dam destroys part of terrestrial plant habitat and changes to rely on these terrestrial plants living resources. The dam was also blocked with the migration routes of migratory fish, affects the species exchange, and changes the reservoir downstream aquatic plants and animals. The river water level changes with the electric power demand pattern which will cause some adverse consequences on the aquatic ecological environment. In addition, the living environment and life cycle of the river water temperature changing will change the aquatic organisms, because of changes in larval breeding, hatching and metamorphosis often depending on the temperature. b) Changing in the number and species. The dam has weakened the peak, adjusted the water temperature, reduced the dilution effect of downstream river, and the plankton greatly increased the number, and distribution significantly changed. Due to the large number of pebbles and sand dam, the river bottom invertebrates lost survival environment, such as insects, shellfish and animal (Rosenberg, 2000).

2) Effects of dams on the environment in the flooded area. a) The wetland landscape reduced. Ecological environment degradation of wetland functions is pejorative due to hydropower development changes the hydrological situation of wetland and water circulation. b) The wetland biodiversity loss. Blocking the river channel change and animal habitat environment will make the quantity of birds and mammals changed. The dam has changed the hydrological and hydrodynamic conditions, the ecological environment system of floodplain wetland is destructed, which leads to the deterioration of regional ecological environment.

\section{Control Measures on Negative Externalities of Hydropower Development}

\section{Ecological Compensation Mechanism}

According to the changing of river ecosystem service value,

Table 1.

Effects of dams on river ecological system.

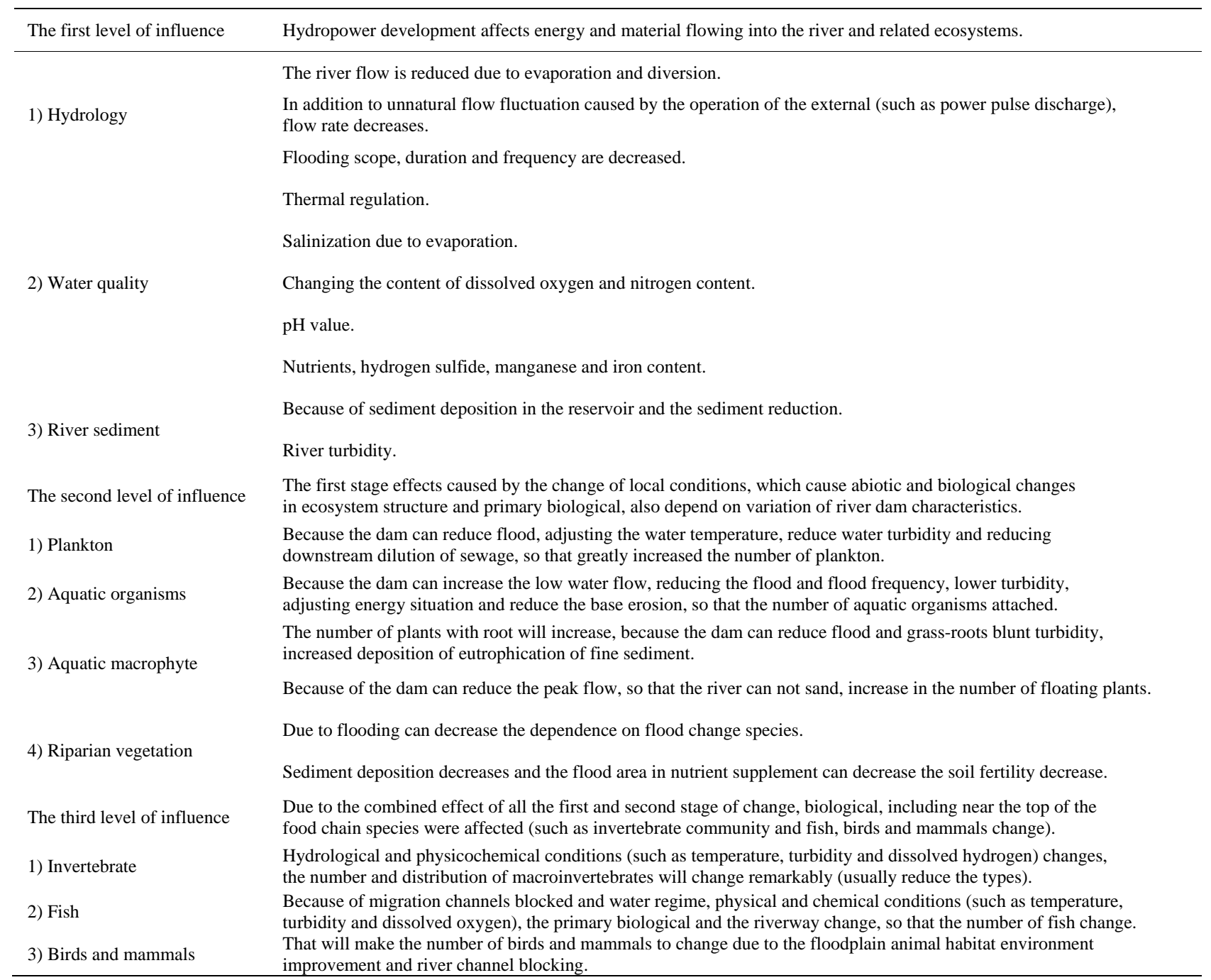


we can take the measure of ecological compensation. In general, the hydropower development of ecosystem service includes power generation, water supply, irrigation, hydropower development, the owners are the main beneficiaries, the persons of the river flows through the city and rural areas also get significant irrigation and water supply benefit. Therefore, the beneficiaries of the river flows through the area should pay compensation in the amount of benefit ratio.

\section{Building Dams Using Modern Technology}

In the planning, design, construction and operation process, we should use modern science and technology and modern engineering technology. In the planning stage, we obtain information environment, using modern geophysical technology to fully understand the dam foundation and the reservoir natural conditions, analysis of the changes before and after completion of environmental factors with the mathematical model and physical model.

\section{Strengthening Environmental Impact Assessment of Dam Construction}

In the development of construction, evaluation and prognostic evaluation value changing by the dam with the natural ecology, social ecology and the environment, reducing the adverse impact on the environment to a minimum, maximizing the overall benefit of project.

\section{Conclusion}

The designers, builders and managers should be the ultimate goal to improve the ecological environment and sustainable development, through the application of modern technology, carrying out environmental impact assessment, to develop means of dam operation mode for the ecological environment. Careful study of negative environmental impacts of dam may bring fully demonstrating the feasibility of a dam construction project environment, changing analysis humanities, social, ecological, natural resources, climate change, land resources, river sediment and other factors may occur, distinguishing the favorable and unfavorable elements, adhere and mitigate the adverse effects of dams on river ecosystem environment, so that every project construction will not only has great economic benefits, but also will promote the sustainable development of economy society, and promote harmony between man and nature.

\section{REFERENCES}

Shiklomanov, I. A. (2005). World fresh water resources. Water in Crisis, 262, 19-20.

Stegner, W. (1992). Where the bluebird sings to the lemonade spring. Living and Writing in the West, 256, 116-120.

Moyle, P. B. (1988). Fishes: An introduction to ichthyology. Englewood Cliffs, 334, 120-126.

Hughes, F. M. R. (1990). The influence of flooding regimes on forest distribution and composition in the Tana River floodplain. Applied Ecology, 27, 475-491.

Rosenberg, D. M. (2000). Global-scale environmental effects of hydrological alterations: Introduction. Bioscience, 50, 746-751. 